\title{
Hydrological Risk Assessment at Praia, Cape Verde
}

\author{
Jose Lino Silva ${ }^{1}$, Joao Garrott Marques Negreiros ${ }^{2}$ \\ ${ }^{1}$ University of Cape Verde - Palmarejo, Praia, Cape Verde \\ ${ }^{2}$ University of Saint Joseph, Macao, China
}

\begin{abstract}
Hydrology modeling became a relevant topic for the Cidade da Praia, Cabo Verde, Africa, due to negative impact risk to local population and its assets. The modeling via Geographical Information Systems (GIS) can help the decision-making process of space occupation and characterization for this type of risk. Under the municipalities of Praia, the phenomenon of flash flood is common, causing soil erosion and landslide. This constitutes a risk for the local habitat, particularly in districts with a lack of strong human infrastructures. To simulate, analyze and generate risk maps using GIS to help this county governance authorities for decisionmaking, thus, becomes the main aim of this article.
\end{abstract}

Keywords-Hydrology, population, Cape Verde.

\section{INTRODUCTION}

The county of Praia in Cape Verde features a large morphological diversity and some adverse weather conditions [1]. Environmental vulnerability and hydrological risk have always existed in this county due to its own territorial morphology derived from the local climate and aggravated by human intervention upon the physical environment. On the other hand, the economic and social changes on the Praia county over several decades and the accelerated pace of the economic growth in recent years have led to strong pressures on the environment, leaving behind a negative imprint on the territories, which sometimes requires huge financial costs to reverse the situation [2].

GIS have the advantage of allowing simulations and develop spatial support systems in the sense of finding a balance in the development of human activities. For example, rainfall takes place with increased frequency in Cape Verde in an intensive and irregular manner. Between the months of September and October, there are records of, at least, one high intensity rain event, causing extensive damage and endangering the lives and safety of the population.

This writing goals the characterization of hydrological risk (flash flood) that the municipality of Praia $(133,000$ inhabitants) is subject to, especially in urban areas, a phenomenon that frequently occurs in regions featuring this dry tropical climate [3]. With this purpose in mind, we intend to produce a set of information that allows to (A) Model the physical environment of Praia county and determine the associated hydrological risks; (B) Provide the mapping of hydrological risk areas based on a surface runoff model; (C) Analyze and quantify the various factors of soil occupation risks associated with climatic, environmental and social aspects; (D) Highlight the importance of GIS in the planning urban areas at Praia.

This research paper is divided into eightmain sections. Starting with this introduction and followed by an overview of hydrological risk, the third section recalls the fundamental concepts of digital terrain models (DTM) and the theoretical references to the current drainage models (D8, NGFLOW and SCS). Section four addresses a review of the literature towards the importance of remoting sensing in risk assessment, particularly on precipitation topics. The following two sections include an overview of the county of Praia.Section 7 reveals the hydrological methodology used for the realization of rainfall simulation, analysis and generation of risk maps. The last chapter expresses some recommendations to the local government of Cape Verde.

\section{HYDROLOGIC RISK}

Territory disordering reflects on the potential danger of flooding, caused by the surface runoff increased and on the dry cargo effect (destruction of vegetation, increased erosion of slopes, soil sealing). However, for a correct assessment of the hydrological risk, it is essential to know the existing rainfall regime in the area. It is known that precipitation is a natural event, which has great variability in terms of its distribution in the planet's surface. This is a phenomenon that feeds the hydrological cycle and is the major factor for surface runoff, infiltration, evaporation, aquifer recharge and alike. Thus, precipitation is an essential element in studies of infrastructures planning and projection. Certainly, measuring rainfall data is crucial for identifying fields with conditions for agriculture, design of water resources, environmental assessment and quantification of soil erosion [4]. 
Within arid regions, the phenomenon of flash flooding can be particularly dangerous for several reasons. Although they are rare, these storms can discharge a large amount of water in a short time. Secondly, these rains usually fall in low permeability soils such as clay by greatly increasing the amount of runoff, overloading the rivers and drainage channels. Sometimes these regions do not have adequate infrastructural conditions to divert water such as manholes, underground holding tanks and retention basins, either due to lack of population, poverty or because the residents still ignore the real risk of flooding. Moreover, the lack of regular rain water to clean water channels can cause flooding because of a large amount of accumulated debris throughout the dry period which are then carried by floods.

Generally, the hydrological risk approach can be broken down into four stages, according to [5]: (A) Analysis of the region morphology by considering their historical values; (B) Survey on the changes and introduced by man (it can serve to counteract the effects or minimize the likely impacts); (C) Survey of existing vulnerabilities due to the presence of man (urban areas) or due to the economic lacking infrastructures; (D) Presentation of the risks/dangers chart and their respective spatial weighting. Note that this last step requires a thorough analysis, taking into account the evaluation of the intensity of risks, vulnerabilities and environmental conditions.

\section{DIGITAL MODEL OF LIFTING (DML) AND DRAINAGE NETWORK (D8, NGFLOW AND SCS)}

Digital Elevation Model (DEM) is a major key element in any hydrological phenomena study. Undoubtedly, the topography of the terrain influences the hydrological flow. However, the advent of GIS based on DEM has facilitated the hydrological modeling at different scales of watershed areas [6]. Figure 1 depicts the DEM in the southern region of the island of Santiago (municipality of Praia), where water spatial distribution in the basin requires the use of spatial data, particular at the borders of the river basins and sub-basins, slopes and drainage channels. Certainly, all these topographic attributes are determined by the DEM.

With regard to the dynamics of hydrological processes and movement of soil, slope is another significant factor. The definition of a slope, [4] considers the formula $\varphi=$ $\Delta Z \frac{1}{100 X}$, where $\varphi$ stands for slope, $\Delta Z$ for the altitude variation and $x$ equals the distance between the center of any GIS cells. Thus, it is possible to determine, at the pixel level, the current direction of the water that will take, allowing the generation of an image with flow

directions. These channels are identified as cell lines, whose flow accumulation exceeds a specific number of

cells. By computing the number of cells above a particular threshold setup for the drainage network, one can determine the accumulated flow in that cell [7]. The algorithm that describes the flow direction became known as the Deterministic Algorithm 8 or D8 [8]. This methodology is based on the fact that water is able to move in eight possible directions, as shownin Figure 2.

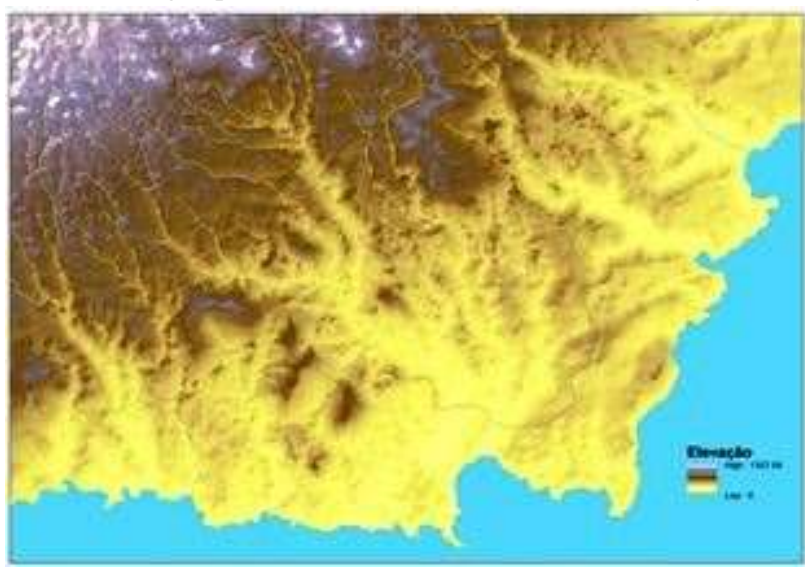

Fig.1: DEM of Praia County.

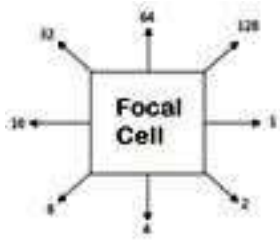

Fig.2: Directions codification of the flow at the cell level.

During the creation of the drainage system with GIS, the first step consists in filling small depressions existence on the model (fill sinks) that arise for geographical data entry errors. The correction of these depressions is an important step for the generation of the river system within the DEM. Thereafter, one delimits the contribution basins that are identified as a set of all cells that flow to a certain target cell from which drain lines are defined (Figure 3).

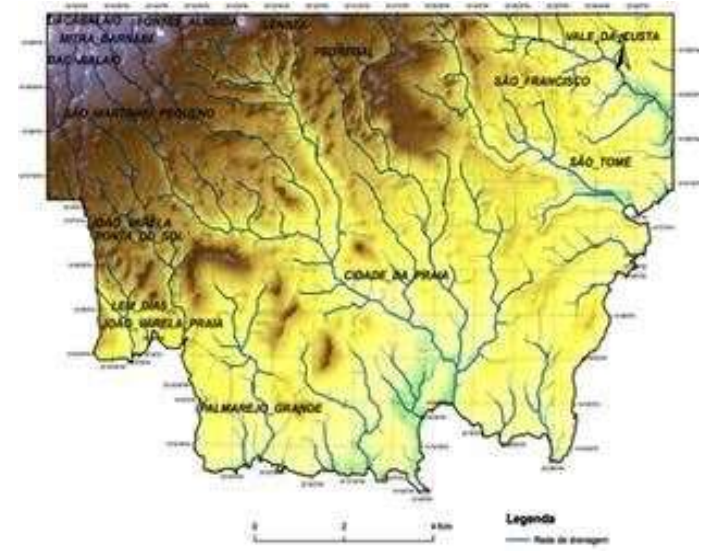

Fig.3: Draining network generated from a DTM. 
In turn, the NGFlow model is based on the DEM as a spatial representation of weather stations, providing the precipitation data records and rainfall time series [9]. In situations where dams can be found, an increase of timely information is needed about the volume, length and release of water. To the input data, one adds the estimated water balance based on the precipitation data, soil storage capacity and potential evaporation. Therefore, the excess flow is formed by water that does not evaporate or infiltrates the soil. In order to calculate

the excess runoff flow, we took into consideration equation 1. The left side of the formula describes the water absorption by the soil in a given time interval. Note that the absorption at time corresponds to the absorption occurred in the previous time, plus the amount of precipitation minus evaporation. The right side of the equation describes the flow. While the soil capacity to absorb water is not met $\left(w(t) \leq w^{\prime}\right)$, the flow rate is zero. At the moment that the soil infiltration capacity is reached $\left(w(t)>w^{\prime}\right)$, it is then possible to determine the flow rate that corresponds to the water surplus (not absorbed by the soil in a given time interval).
$\frac{W(T)}{\ddot{A}}=\frac{W(t-1)}{\ddot{A}}+P(t)-E(t) S(t)=\frac{\left(W(t)-W^{\prime}\right)}{\ddot{A}}(1)$

Under this equation, $S(t)$ stands for the flow rate at a given time of the simulation, $P(t)$ indicates the precipitation, $E(t)$ represents the evaporation; $W(t)$ means the soil capacity to absorb water while $W$ specifies the water holding capacity of the soil where $\ddot{A}$ denotes the considered time interval.

The SCS-CN (Soil Conservation Service - Curve Number) method is widely used in hydrology for its simplicity and quality of results in estimating the direct surface runoff from a precipitation event [10]. In this model, the main elements that determine the surface runoff volume (effective precipitation) are the retention of rain on the ground depressions and infiltration. This effective precipitation estimate considers three variables: (A) precipitation in the time interval; $(B)$ soil characteristics and moisture which defines the retention potential; $(C)$ loss on early rainfall. As expected, the flow rate has an influence on the hydrological dynamics of soil due to its action on the surface, on the mass movement and on the flow time or concentration. The evaluation of this speed can be carried out by the Soil Conservation Service (Table 1).

Table.1: Speed in m/s based on the slope and soil occupation (Source: Soil Conservation Service, 1972).

\begin{tabular}{lllll}
\hline Slope in \% & Forests & $\begin{array}{l}\text { Natural } \\
\text { grasslands }\end{array}$ & Slope in \% & $\begin{array}{l}\text { Almost bare } \\
\text { grounds }\end{array}$ \\
\hline $0-4$ & 0.3048 & 0.4572 & $0-2$ & 0.6096 \\
\hline $4-8$ & 0.6096 & 0.9144 & $2-4$ & 0.6096 \\
\hline $8-12$ & 0.9144 & 1.2192 & $4-6$ & 0.6096 \\
\hline $12-15$ & 1.0668 & 1.3716 & $6-10$ & 0.9144 \\
\hline & & & $10-12$ & 1.2192 \\
\hline
\end{tabular}

The estimated speed computation shown in the previous table can, hence, be performed by equation 2 (S represents the slope or gradient). In turn, the coefficient $K$ is estimated taking into account Table 2.

$$
V=K \times S^{0.5}(2)
$$

Table.2: K coefficient value of the flow speed assessment (Source: Soil Conservation Service, 1972).

\begin{tabular}{ll}
\hline Types of areas & Speed \\
\hline Forest with a lot of foliage on the soil & 0.076 \\
\hline Area with little cultivation & 0.152 \\
\hline Meadow-grasses & 0.213 \\
\hline Cultivated land & 0.274 \\
\hline Bare ground & 0.305 \\
\hline Flowlines & 0.457 \\
\hline Paved surface & 0.61 \\
\hline
\end{tabular}

The time of flow path (the water flow distance from one location to another) is also an important variable in hydrological modeling. According to NRC [11], the flow time between two points in a water basin is determined on the basis of the principle of equation 3(Tp: flow path time; $n$ : roughness coefficient; l: stream length; $P_{24}^{0.5}: 24$ hours average of rainfall over the last two years; S: slope

$$
\begin{gathered}
\text { or gradient). } \\
T p=\frac{0,007 x(n l)^{0.8}}{P_{24}^{0.5} \times S^{0.4}}(3)
\end{gathered}
$$

The determination of the roughness coefficient presumes the assessment of soil conditions and occupation. To this end, the NRSC has set a coefficient, complying with these factors as it is described in Table 3.

Table.3: Index of roughness, according to NRSC [8]. 


\begin{tabular}{ll}
\hline Hard surfaces (concrete, asphalt...) & 0.011 \\
\hline Fallow soil & 0.05 \\
\hline Cultivated land & \\
$\quad$ With coverage < a 20\% & 0.06 \\
$\quad$ With coverage > a 20\% & 0.17 \\
\hline Formation of meadow-grassland & \\
Grassland & 0.15 \\
Dense grassland & 0.24 \\
Bermudagrass & 0.41 \\
\hline Forest & \\
Relatively high density & 0.8 \\
Low density & 0.4 \\
\hline
\end{tabular}

The calculation of the discharge assumes this rational method for determining the specific discharge of each pixel in the runoff basin. It can be computed with the SCS estimate as described in equation 4 (Tp: time; $Q$ : discharge peak for each cell $\left(\mathrm{m}^{3} / \mathrm{s}\right) ;$ : : pixel area (ha); I: precipitation average intensity $(\mathrm{mm} / \mathrm{min}) ; \alpha$ : flow coefficient). $Q=0.167 \times S \times I \times \alpha(4)$

By definition, flow rate equals the volume of a fluid flowing through a given section of a free channel per time unit (a free channel can be a river or a pipe, for instance). Thus, one can determine the flow rate as $F=A \times V$, in which $A$ stands for the area in question and $V$ for the speed of flow expressed in $\mathrm{m}^{3} / \mathrm{sec}$. In order to measure this speed rate of a water course, one typically uses the windlass (an apparatus provided with a propeller and a rotation meter). This measurement is universally used to determine the flow of a natural watercourse and consists in determining the cross-sectional area and the average speed in any section.

Finally, the surface runoff in rivers and channels is represented mathematically by two differential equations

that describe mass or volume preservation and the quantity of flow movement, named the equations of Saint Venant [12] where $Q$ equals volumetric flow rate, $A$ is the area of the wet section, $X$ stands for the distance in the longitudinal direction, $t$ denotes time and $q L$ represents the input or output flow per unit of width.

$$
\frac{\partial Q}{\partial X}+\frac{\partial A}{\partial T}=q_{L}(5)
$$

\section{IMPORTANCE OF REMOTE DETECTION IN RISK ASSESSMENT}

Remote sensing refers to the obtaining process of information about objects or areas via electromagnetic radiation without being in direct contact with them [13]. This practiceis based on the principle that all electromagnetic radiation presents fundamental properties, behaving in a predictable way, according to the wave theory. It is achieved through a series of steps that go through the detection and recording of energy reflected or emitted by the objects and subsequent processing, analysis and application of the recorded information. Sensors capture the fractions of the emitted spectrum of electromagnetic energy from objects of the earth's surface, converting them into a paper image or a digital numerical signal.

In order to be able to extract information from the remote sensing data, it is vital to know the behavior of the spectral reflectance of the different bodies as well as the factors that interfere in its behavior.It is called the electromagnetic spectrum.Technically, this spectrum is the complete range of all types of electromagnetic radiations, ranging from radio waves to gamma radiations. The figure below shows the different bands of the electromagnetic spectrum.

\section{THE ELECTROMAGNETIC SPECTRUM}

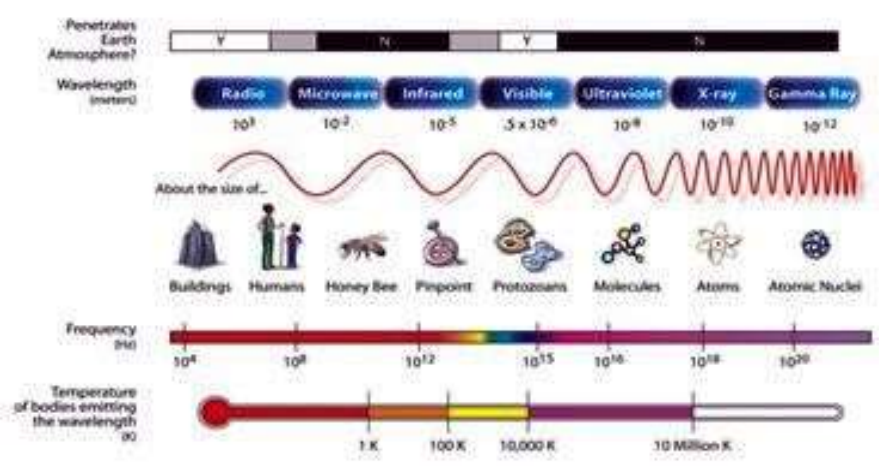

Fig.4:The range of visible light to the human eye is also a component of this electromagnetic radiation picture. However, its range is very small compared to that of other wavelengths.

Remote sensing has become an important alternative for research and practical applications in various domains including the environmental sector such as geography, geology, water resources, agriculture, forestry, meteorology, oceanography and civil engineering. This is particularlynotablefor collecting data on unreachable regions such as high altitude mountains and cold regions where continuous monitoring by humans is usually quite impossible.

Information by remote sensing can be acquired through satellites or airplanes. Again, remote sensors use electromagnetic spectra for global observations of objects on the Earth surface or even on the limit of the Earth's atmosphere (in the case of suspended aerosol particles, for instance). Each object has specific properties of absorption and reflection of the energy received by the sun. Technically, remote sensors pick up that electromagnetic energy reflected by the surface of objectsto determine the type of cover and its properties. 


\subsection{Remote detection and precipitation}

Precipitation is the phase of the hydrological cycle that exhibits the greatest spatial variability in this study. Its measurement is conventionally measured by pluviometry stations which provide data for a limited region. The World Meteorological Organization (WMO) recommends the ideal number of rainfall data logs per square $\mathrm{Km}$. For small islands, the recommendation is for a registration station for 250 square $\mathrm{Km}$. For urban areas, a check-in station is recommended for each 10 to 20 square $\mathrm{Km}$.

The precipitation measurement at the record stations is made from the height of the water slide which would be accumulated on a flat surface if no loss occurred. Typically, intense precipitation is considered to be one originating from the same meteorological disturbance, whose intensity exceeds a certain value in millimetres $(\mathrm{mm})$. Generally the variation of this disturbance goes from a few minutes to a dozen hours and the area affected by it can range from a few square $\mathrm{Km}$ to thousands of ones. In extensive continental regions, the collection of precipitation data by land stations is hampered by the low density of collection points, making spatial estimates of precipitation as a useful and low-cost resource.

Estimatesgive a good impression of the overall distribution of cloud cover and precipitation. Satellite images have been an important means of obtaining precipitation data. Its importance is even greater in places where there is a low density of ground stations. The continuous data for a wide area is obtained only by means of geostationary satellites of high temporal and spatial resolution. In these regions, according to [14], meteorological satellites are the only realistic means of monitoring spatial and temporal distribution of precipitation with a high level of accuracy.

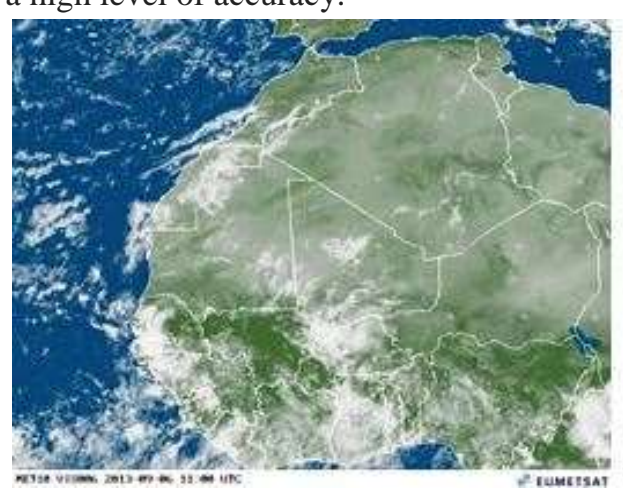

Fig.5: Image of the Meteosat satellite of the visible and infrared spectrum.
The estimation of precipitation by satellites has been done using images of several satellites and in several bands of the electromagnetic spectrum. The use of these spatial images for the meteorological forecast was the first civil application of satellite remote sensing [15]. The physical and optical properties such as reflectivity and emissivity depend on both the characteristics of the clouds and the wavelength of the radiation observed by the satellite. However, there is no direct relationship between the electromagnetic spectrum data measured on the clouds surface and the amount of precipitation observed [16]. As an example, techniques developed for tropical regions may not be applicable to extratropical regions.

A paradigmatic example is the principle of the precipitation estimation by satellite images in the visible spectrum of electromagnetic radiation. This method is based on the fact that the brightness of the sun reflected by clouds can be a reasonable indication of its thickness and, consequently, of the volume of water in its interior. Similarly, temperatures at the top of the clouds by sensors in the infrared range are indicative of their thickness or vertical development where the greater the thickness, the higher precipitation rate [17].

The top cloud information reveals the temperature and reflectance that are treated by statistical methods to estimate cloud precipitation over its entire length. This estimate is two-dimensional (VIRS sensors). Under the microwave spectrum (frequency lower than $50 \mathrm{GHZ}$ ), a great emission sensitivity of water vapor, clouds, rain and properties of the Earth surface can be found. These frequencies are very useful for the discrimination of surface type, cloud content (hydrometeors) and precipitation intensity [18].

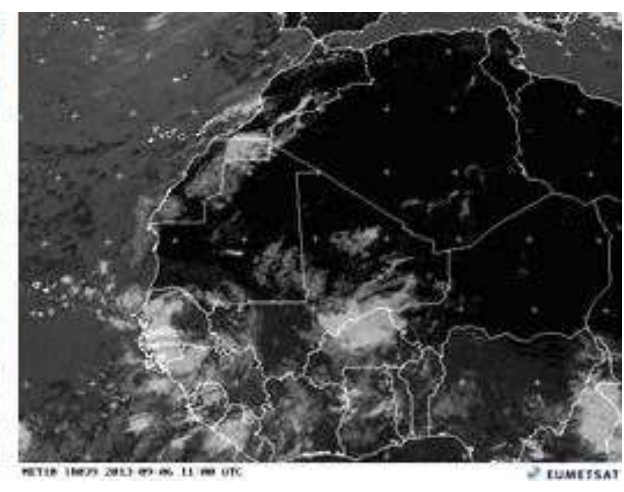

of the relatively high temperature at the top [18]. However, it has become evident that not all the clouds with a cold top layer effectively produce precipitation. Therefore, the infrared estimates can be made locally only, providing poor results when transposed to other regions [14].
Precipitation indices are usually derived by reading the temperature through infrared radiation. Yet, there is some uncertainty about the data presented. The hypothesis that cloud height is tied to its thickness works well for convective ones but is problematic for nimbostratus ones whose rainfall estimates are often underestimated because 


\subsection{Meteorological satellites}

Meteorological satellites are used to monitor Earth's weather and climate but can also serve to monitor human activities such as city lighting, burning, pollution levels and deforestation, for instance.The Geostationary Operational Environmental Satellite (GOES) satellite series is the leading meteorological satellite family managed by the United States National Oceanic and Atmospheric Administration (NOAA). GOES images and data seek to provide a steady stream of reliable information used for weather forecasting and surveys. These satellites are geostationary, that is, they have the same Earth speed of rotation and are stationed on a fixed point of the equator, which allows them to observe continuously the same area.To date, NASA has already launched 15 GOES and is in development to release GOES Q in 2015.

The GOES are located in a geostationary orbit about $35,800 \mathrm{~km}$ above the Earth's surface. Under these conditions, the GOES family satellites provide important information on Atlantic and Pacific weather conditions, especially on precipitation estimates, tropical storm movements and snow cover in extra-tropical regions. These satellites carry two types of components, namely a sensor that captures multiple wavelengths of the electromagnetic spectrum (visible and infrared) and an aerosol sensor of the Earth's atmosphere to obtain temperature and humidity data.

In addition to the GOES series, there is the Tropical Rainfall Measuring Mission (TRMM), considered the first global precipitation measurement equipment (GPM). Launched in November 1997, it is a joint project between NASA (American Space Agency) and (JAXA), Japanese Agency for Aerospace Exploration, with the specific objective of monitoring rainfall in the tropics and verifying its influence on the global climate.

The TRMM satellite holds a $405 \mathrm{~km}$ high, with a very steep orbit between $35^{\circ} \mathrm{N}$ and $35^{\circ} \mathrm{S}$ latitude and holds a translation period of 91 minutes, allowing a relatively high spatial and temporal resolution. The TRMM satellite sensors sweep a path with several hundred Kmwidth, monitoring most of the tropics daily. This orbit allows the satellite to remain over the tropics most of the time [19].There are four main sensors on board that use different spectra and bands to collect information [20]:

$>$ Visible Infrared Radiometer (VIRS) is a passive transverse range scanning radiometer with five channels centred at $0.63,1.6,3.75,10.8$ and 12 $\mu \mathrm{m}$ wavelengths, providing high resolution at cloud cover, cloud type and cloud top temperature. Under this band, the radiation does not penetrate the clouds so the temperature values collected refer to the top of the clouds.

$>$ Microwave Imager (MI) is a passive multichannel $(10.65,19.35,37.0$ and $85.5 \mathrm{GHz})$ microwaves radiometer with vertical and horizontal polarization. This sensor provides information on the integrated content of precipitation column, liquid water and cloud ice, rainfall intensity and types of rain.

> Precipitation Radar (PR) is a scanning radar (active) operating at $13.8 \mathrm{GHz}$ and measures the distribution of precipitation in three dimensions. In parallel, it defines the depth of the precipitation layer.

$>$ Lightning Imaging Sensor (LIS) is an optical (passive) sensor that detects and locates lightning events under the neutral oxygen range $(0.777 \mu \mathrm{m})$.

Despite the importance of the satellites in the provision of precipitation data and the great advances achieved since the launch of the first meteorological satellite, there is still some imprecision in the estimation of precipitation values.Unsurprisingly, the accuracy of the spatial and temporal distribution of precipitation is fundamental for a wide range of applications of climate modelling and generalization, from global to local [21].

One approach of measuring the accuracy of satellite precipitation data is to collect and compare data series in situ. It is assumed that the cold top clouds obtained in the infrared $(11 \mu \mathrm{m})$ range of the GEOS satellite is correlated with the high precipitation rates. In general, this indirect approach provides good results when precipitation estimates are made for a high spatial and temporal scale and the tendency for increased uncertainties for instantaneous estimates of precipitation at smaller scales [22]. However, the hydrometeor information provided by the satellite in the microwave range on oceans allows accurate information on precipitation estimates.

As well, the extrapolation of data associated with the continuous feature in space allows the estimation and spatial distribution of the phenomenon to areas far from the point where historical series are recorded. For example, rainfall is characteristically a continuous phenomenon in a limited space but, however, rainfall measurements are made only at some points on the terrain. Of course, the extrapolation of the data observed for the whole area must be done in a very careful way.

\section{THE CITY OF PRAIA}

The archipelago of Cape Verde is located in the Atlantic Ocean, approximately $450 \mathrm{~km}$ from the West Coast of Africa, between the latitude of $14^{\circ} 48^{\prime} 00$ and $17^{\circ} 12^{\prime} 13$ " 
North and the meridians $22^{\circ} 23^{\prime} 59^{\prime \prime}$ and $25^{\circ} 20^{\prime} 40$ " West . This archipelago consists of 10 islands and 8 islets, organized into two groups, according to each geographic location: Windward and Leeward. The archipelago has a total land area of $4033 \mathrm{~km}^{2}$ whose corresponding coast line extent is $1,020 \mathrm{~km}$.

Cape Verde's climate is part of an extensive range of arid and semi-arid climates in the heart of the Sahelian region (situated between the subtropical high pressures of the Atlantic and the equatorial low pressures). This track of African territory (Senegal, Mauritania, Mali, Burkina Faso, Chad, Sudan, Ethiopia, Erithrea, Djibouti and Somalia) has a precipitation regime, ranging from 150$300 \mathrm{~mm}$ per year.

The county of Praia is located in the south of the Santiago islandand covers an area of $102 \mathrm{~km}^{2}$ (about $10 \%$ of the surface of the island of Santiago). It is bordered to the North by the mountain of Antonia Peak and to the South by the limits of the maritime coastline. Administratively, it has borders with the municipalities of São Domingos and Ribeira Grande de Santiago.

Towards morphology, the elevations of the islands of Santo Antão, St. Nicholas, Santiago and Fogo reach an altitude above $1,300 \mathrm{~m}$. Yet, the highest altitude corresponds to Pico on Fogo Island, with 2,829m, followed by the Crown Top on the island of Santo Antão with 1,985m. The Antonia peak in Santiago reaches 1,395m and Monte Gordo, in St. Nicholas, presents

1,304m. By considering the geomorphological characteristics of Praia, there were sharp erosions lately and, along with the poor vegetation cover, it creates a positive situation for dynamic erosion (Figure 6). The existing valleys in the area are relatively well embedded between the highlands (achadas), among which some relevant elevations stand out, such as the Hill of Vacas with 392m, the Ilhéu or Hill of São Filipe with 274m, Red Hill with 195m, Hill of Gonçalo Afonso with $235 \mathrm{~m}$ and the Hill of Ilhéu with $259 \mathrm{~m}$.

The drainage networks extend from the highlands of the North (Hill of Rui Vaz) to the South of the county, flowing into the Atlantic. As it can be observed from Figure 6 and

7 , there is a main basin where there is a set of flow networks that converge downstream. It turns out that the urban area of the municipality is located at the crossroads of these drainage networks. However, the existing security infrastructure cannot always withstand the water discharges coming from upstream areas.

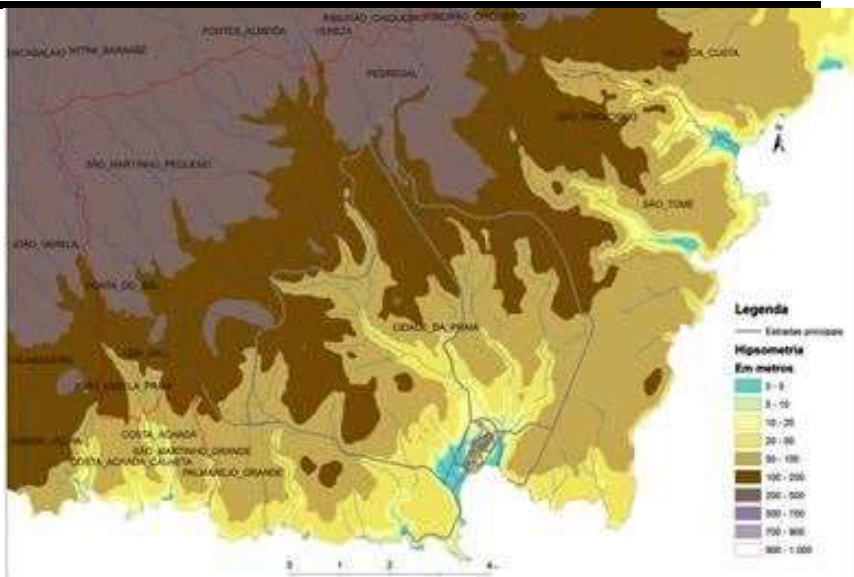

Fig.6: Hypsometric southern map of Santiago Island.

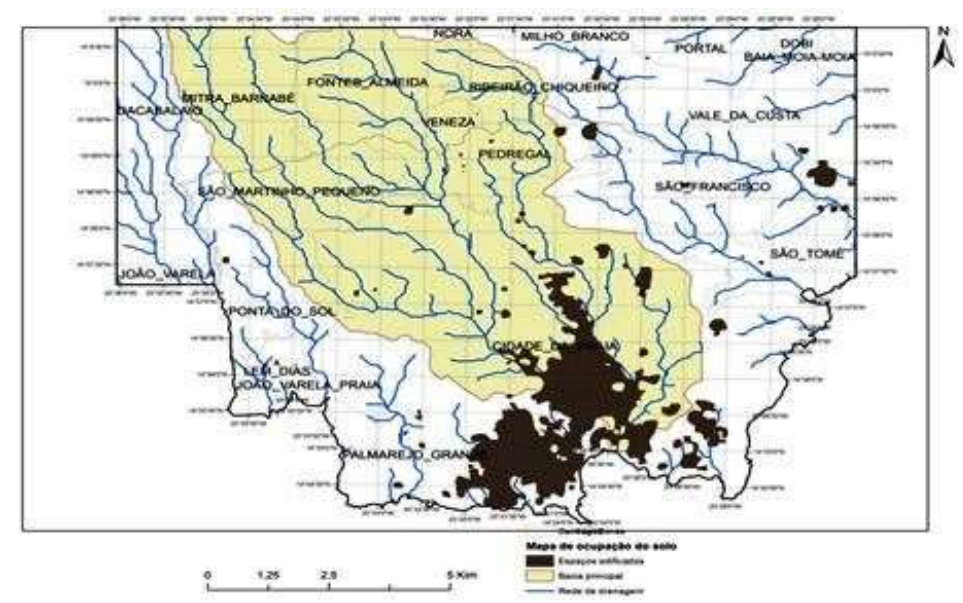

Fig.7: Drain main basin, edification areas and network drain.

The average annual rainfall in the Cape Verde archipelago is no more than $300 \mathrm{~mm}$ in the lowlands (less than $400 \mathrm{~m}$ high). According to [23], the precipitation of downward trend has been recorded since the 60s, reflected negatively on the conditions of farming and water supply. The areas under the influence of hot and dry air masses that blow from the eastern quadrant during the Harmattan (December/January) are the driest, corresponding to an average rainfall of only $150 \mathrm{~mm}$. In spots located more than $500 \mathrm{~m}$ above sea level and exposed to the trade winds, rainfall can exceed $700 \mathrm{~mm}$. In relation to water balance, it is considered that about $20 \%$ of the precipitation water is lost by surface runoff, $13 \%$ goes towards aquifers recharging and $67 \%$ will disappear by evaporation [23].

However, extreme precipitation in the form of flash floods is a phenomenon that occurs in all latitudes, including arid regions and desert climates. This phenomenon has been a reason for concern to the scientific community due to its increasing frequency as a result of recent climate changes. These effects of extreme precipitation are sometimes more serious due to the existing lack of 
vegetation cover that could reduce the impact on the ground. Moreover, notwithstanding the existence of side protection dikes, certain cross-sectional passages of circulation in the city streams do not hold the sufficient height to allow the flow of water when intensive precipitation occurs (Figure 8).

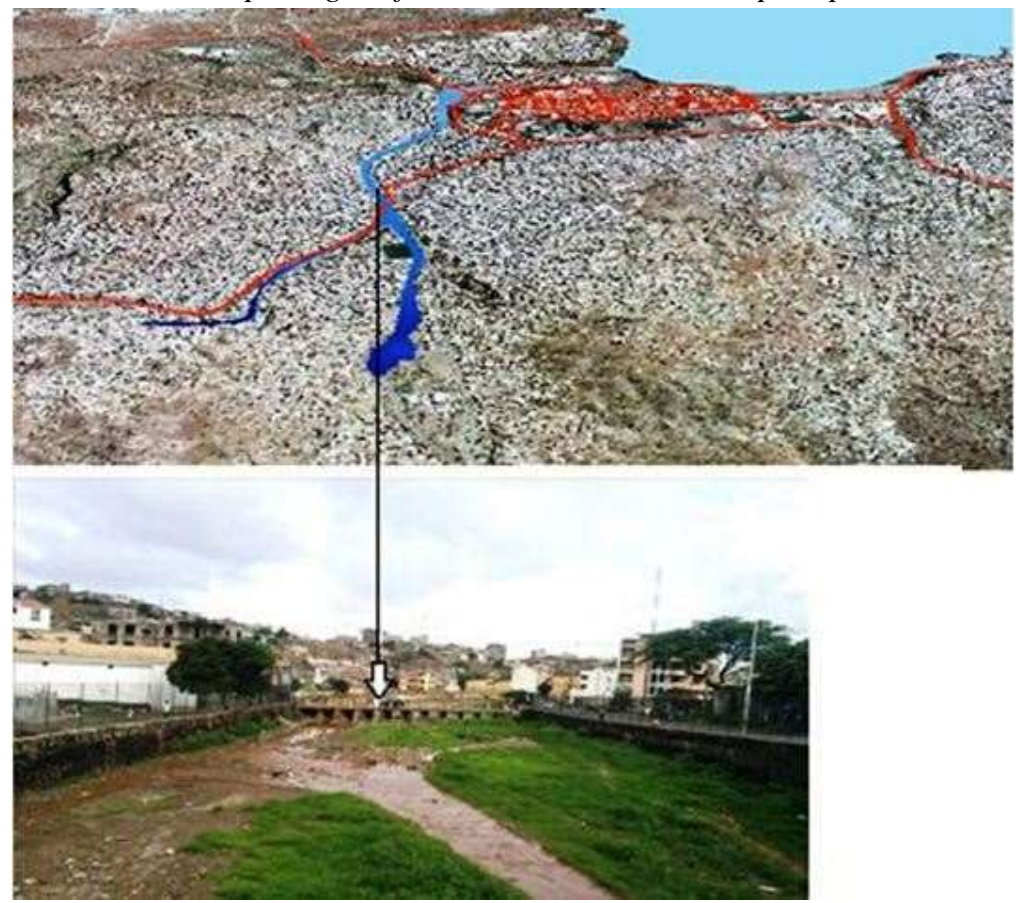

Fig.8: Superficial draining at Safende riverside.

\section{THE HYDROLOGICAL METHODOLOGY}

The present hydrological risk simulation is based on a model with three main components: (A) Flow module, in which considers the various layers of soil types/occupation and of precipitation; (B) Flow path time module, in which the DEM and flow rate are considered; (C) Discharge module, which results from the interaction of the fallen precipitation and the pedagogical and geomorphological processes characteristics. As expected, the different layers interact together, having an influence on the runoff dynamics. For this research, the water discharge at the end of the drainage basin was simulated. The graphical user interface provided by the Model
Builder is significant, as most of the functions are already integrated within ArcGIS (Figure 9). The first component is the flow. Based on the SCS procedure, several parameters are taken in consideration such as the Curve Member, the initial infiltration and the potential one. These elements play a key role in the final activity when determining the flow coefficient that is obtained by the ratio between the total precipitation and the flow amount. This calculation presupposes the raster format associated to all layers: soil type, foregoing moisture of soil (amount of moisture before precipitation), land use, precipitation and DEM. The intermediate results obtained are the curve number, initial infiltration and maximum potential of moisture retention. 


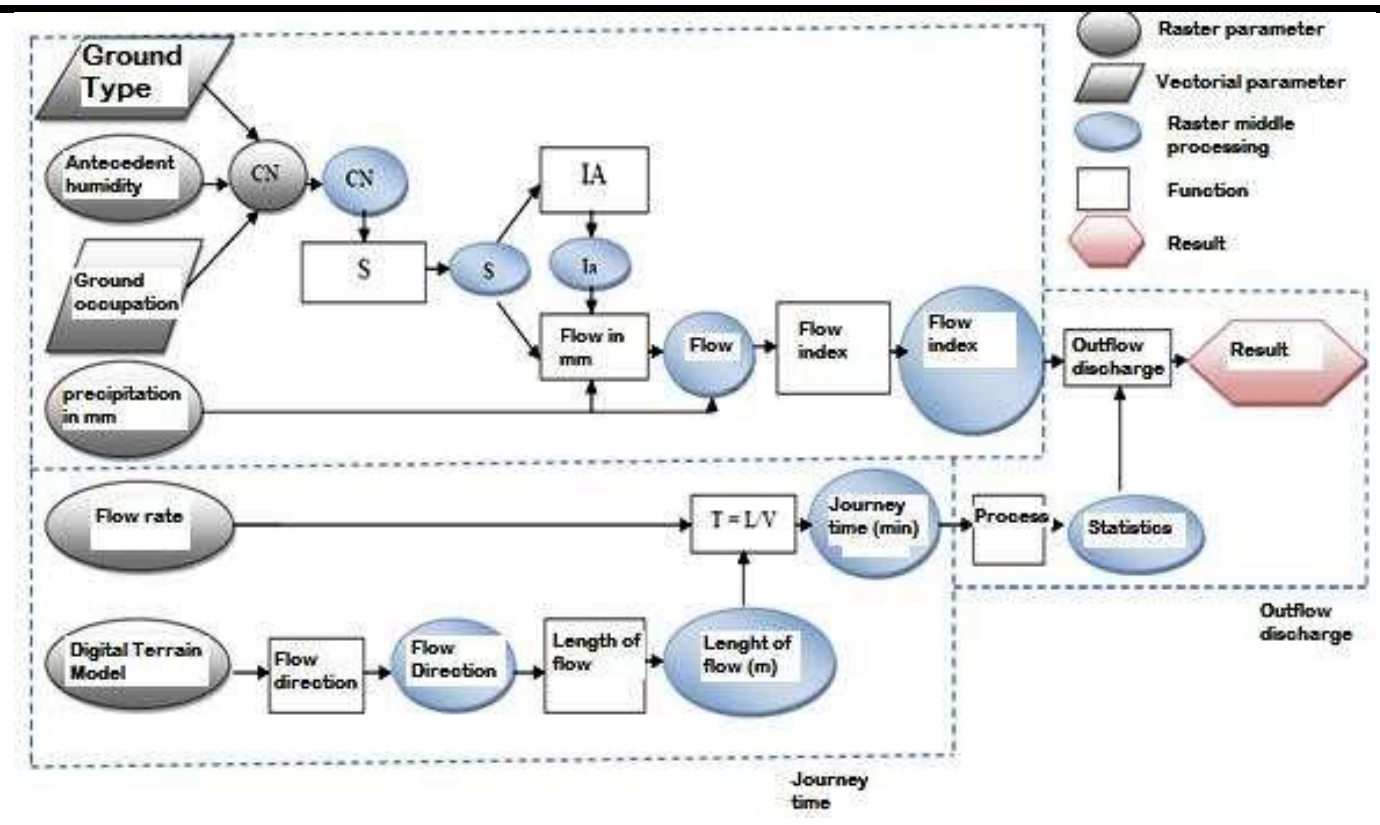

Fig.9: Simulation model for the hydrologic flow.

For framing soil types, it was considered the different soil groups according to the FAO classification [24]. The map of Figure 10 shows the predominant soil types of the county of Praia. As demonstrated, there is a predominance of the Xerossol class that is distributed throughout the northern and northwestern regions of the county of Praia. These soils display a reddish coloring of great thickness. Next, in terms of expressiveness, there are the Cambisol soils, which are little developed soils from non-limestones formations. These soils are usually associated with rocky outcrops, often being characterized by a high proportion of stony elements. One can also identify lithosols belonging to the group of non-climatic erosion mineral soils, which are young, little evolved and associated with outcrops of hard consolidated rocks and basalts. There is still a small portion of undefined soils, which occupies the Plateau neighborhood of Praia.

The foregoing humidity is a parameter that can be modified, depending on the time acclimatization: condition I for dry soils, condition II for moderate soils and condition III for wet soils. Under the land layer drawn from Landsat TM5 images (Figure 11), one can see a predominance of bare ground and rocks in over $80 \%$ of the county of Praia's area. However, there is some scattered green area, consisting of bushes and acacia trees, a species that was introduced in the last 40 years, framed in the national afforestation program.

The discharge makes up the final phase of the flow process. This index takes place at the pixel level (see equation 4 and 5) and, subsequently, it is followed by the accumulation of the discharges, resulting on the flow output. As expected, the total flow in the drainage basin is obtained by the sum of discharges. Finally, we proceed to the discharge values reclassification by the equidistance of the flow path time. In this case, we selected a temporal equidistance of every 30 minutes.

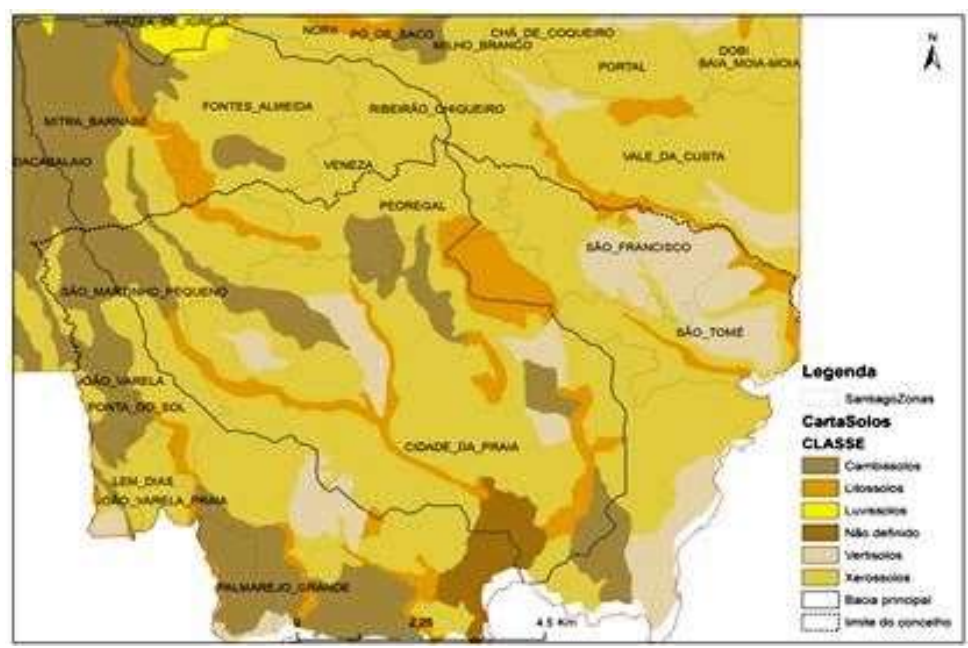

Fig.10: Soil southern map of Santiago Island. 


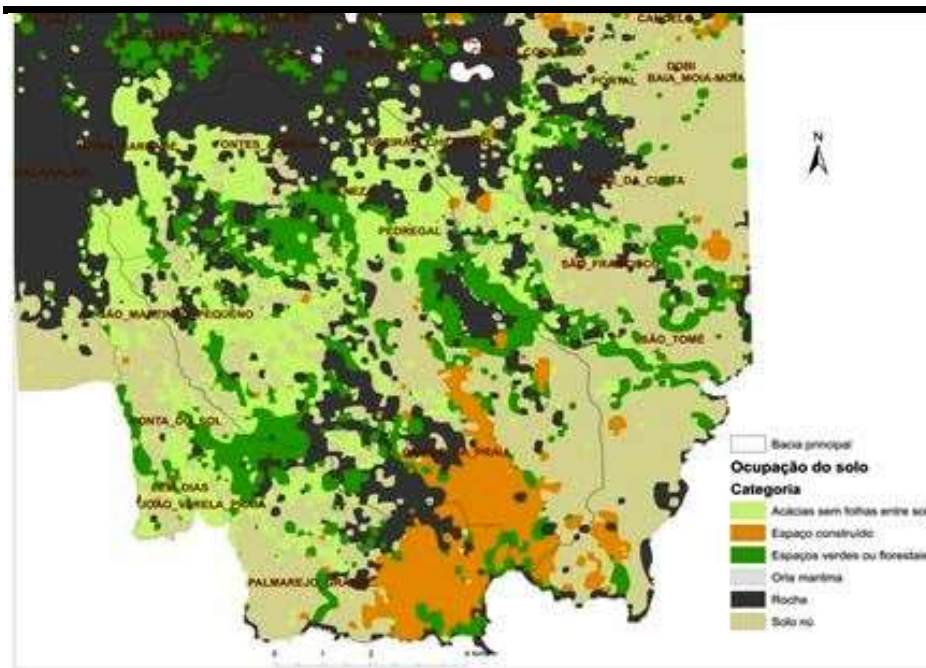

Fig.11: Soil map occupation in the southern island of Santiago.

\section{The county of Praia: simulation findings}

The precipitation data was obtained from the sensor 3B42 of the TRMM satellite. The historical rainfall records indicate some variation of rainfall occurring in the county. As a rule, higher areas receive a greater amount of rainfall as shown in Figure 12[4]. The central region of the island matches with the areas of higher altitudes whilst lower precipitation rates are situated along the coast. As a reference, the county of Praia presents an annual variation between $73-163 \mathrm{~mm}$ of rain.

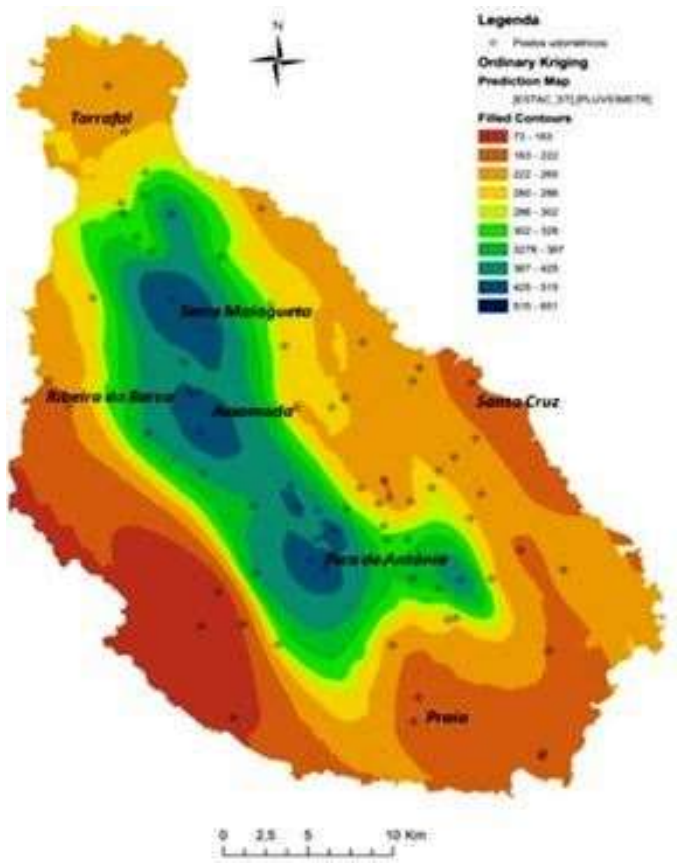

Fig.12: Average precipitation map of Santiago Island [4].

It is particularly notable that the TRMM satellite estimates precipitation in a resolution of $0.25 \times 0.25$, corresponding to an area of $2,162 \mathrm{~km}^{2}$. Given the size of Santiago, approximately $900 \mathrm{Km}^{2}$, this resolution covers 2.4 times the island of Santiago. In order to carry out this study, it was considered the rainfall data occurred on October 22, 2010 (Figures 13 and 14).

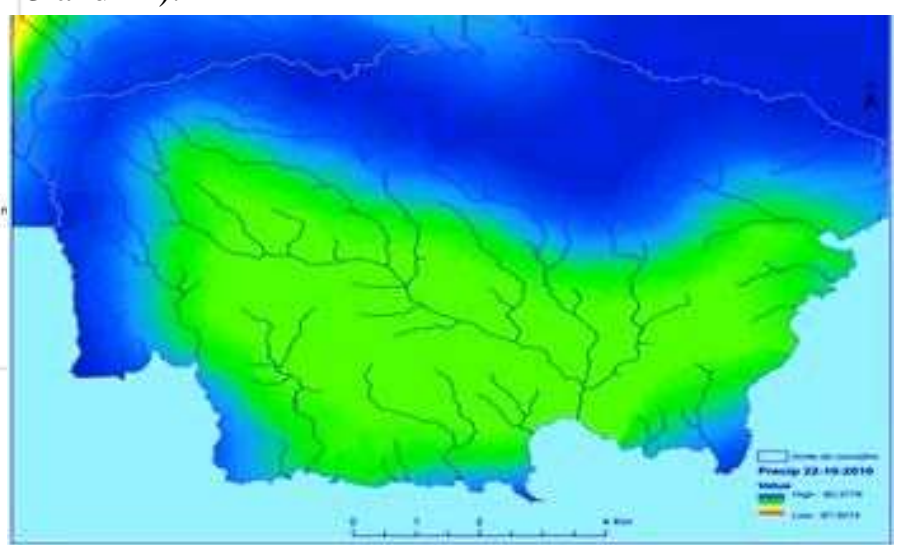

Fig.13: Precipitation map on October 22, 2010.

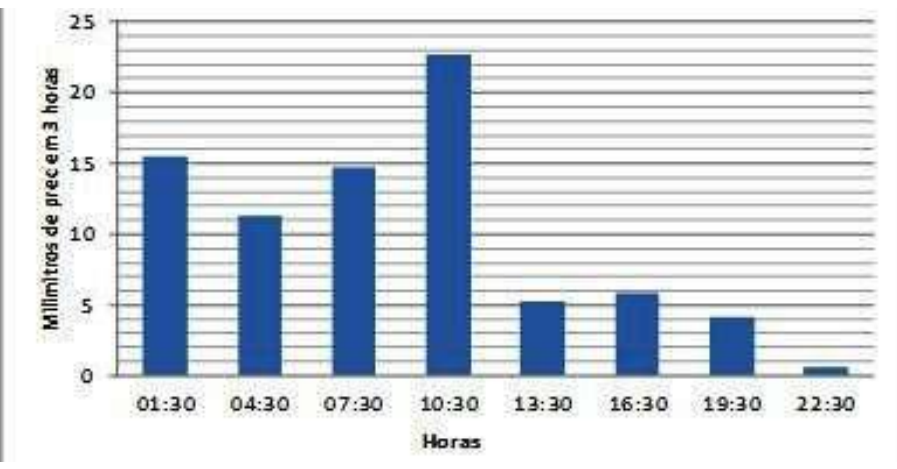

Fig.14: Time precipitation distribution on October 22, 2010.

By definition, the potential infiltration presents the soil's capacity to retain water. Figure 15 illustrates the sectors with greater retention capacity, according to the existence of some dispersion towards the infiltration potential level. These differences are linked to the pedagogical features, degree of vegetation cover, soil occupation and land use. As one might expect, the built-up areas, rocky zones and bare ground spaces are generally of lower potential retention, implying a higher degree of surface runoff.

The flow path time is another significant variable as far as it influences the flow volume in a specified section of the basin, either in volume or in terms of duration. The approach used for determining the flow time formula of section 3 . In a simplified manner, it defines the flow time as the ratio between the flow length and the average speed over the entire 
area of the basin. Subsequently, the stream length is used to estimate the flow time for its relationship with the average velocity of the basin flow. Afterwards, this flow time is reclassified every 30 minutes and applied to the basin for the delimitation purposes of the different patterns. Thus, spaces are shown after having been reclassified according to the flow path time. Figure 16 characterizes the flow time of surface runoff generated from the ratio between the watercourses length in different parts of the basin and the average speed recorded across the basin. Certainly, the flow time is shorter as it moves towards downstream.

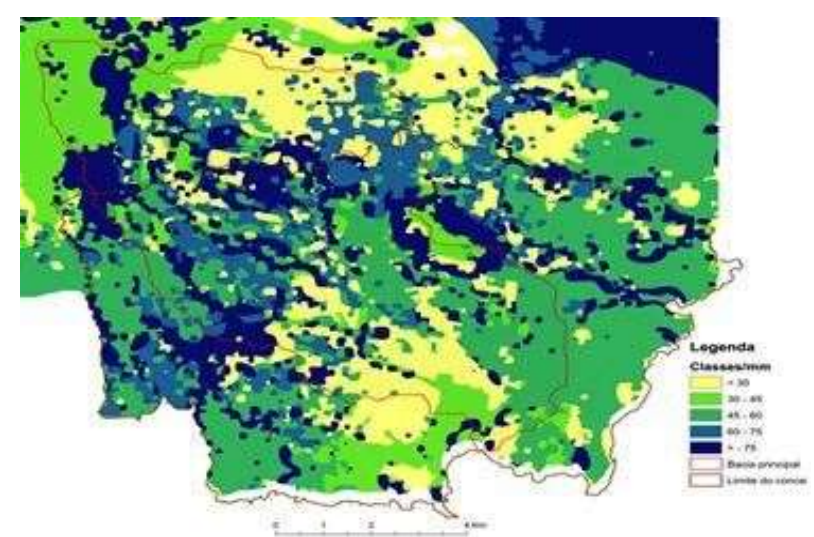

Fig.15: Potential infiltration map in mm at Praia County.

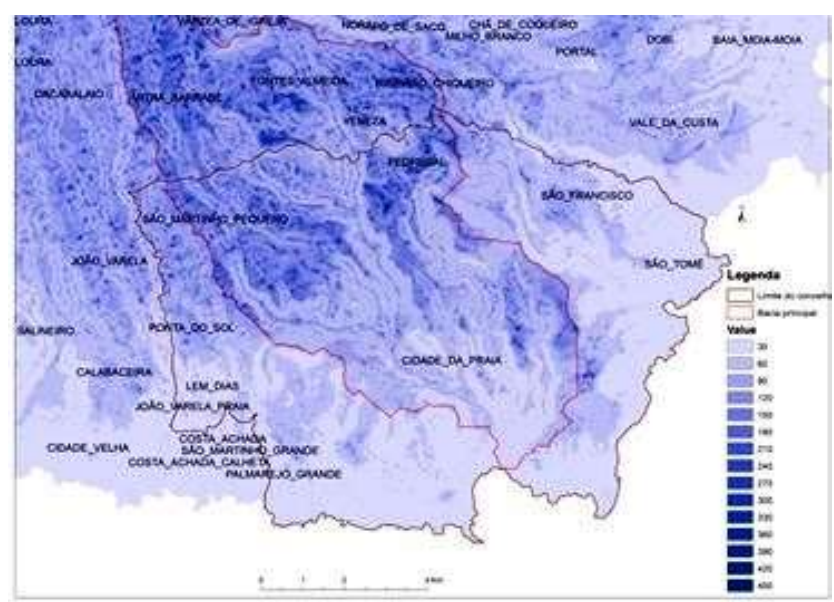

Fig.16: Time map of flow route.

The flow speed involves the $K$ coefficient and the relief slope of the basin. After an analysis of the basin conditions for determining this constant, we chose the value 0.305 , resulting from the fact that most of the space within the drain basin is almost a bare soil. It is noted that the average flow velocity is $1.9 \mathrm{~m}^{-1}$, with the minimum speed of $0.053 \mathrm{~m}^{-1}$ and a maximum of $6.49 \mathrm{~m}^{-1}$. As expected, higher speeds occur in the areas of greater slope, which are well represented in regions further north of the county, matching with the most mountainous areas.

The discharge is the last element obtained from the overall model. This is obtained by the interaction of rainfall parameters in $\mathrm{mm} / \mathrm{min}$, flow time and infiltration potential (soil capacity to retain water). From this latter factor, we may obtain the flow coefficient (effective precipitation). Subsequently, the precipitation that was initially in $\mathrm{mm}$ per hour is now converted to mm per minute in order to make the discharge reclassification in every 30 minutes easier. It should also be noted that the discharge is initially obtained at the level of the pixel and reclassified in areas depending on the flow path time by ArcGIS 10 Spatial Analyst (Zonal Statistics function).

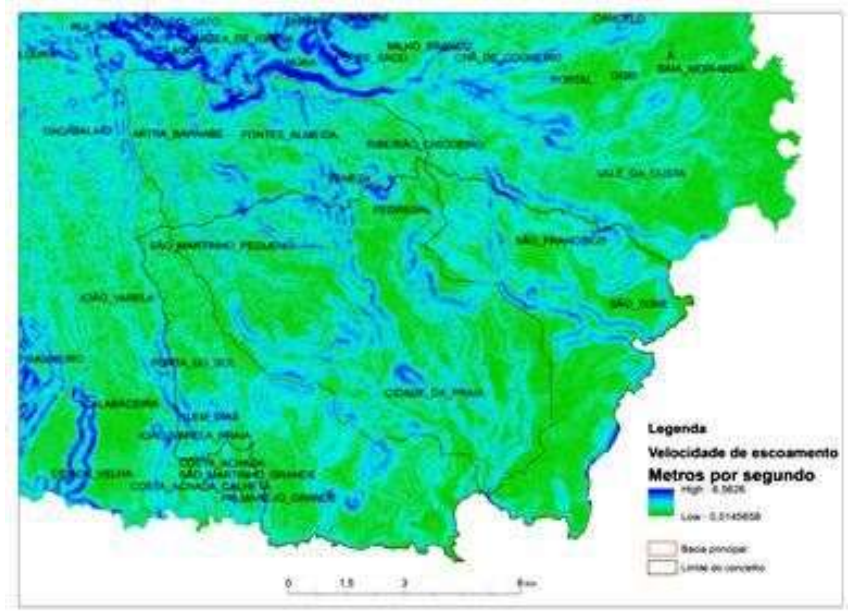

Fig. 17: Flow speed.

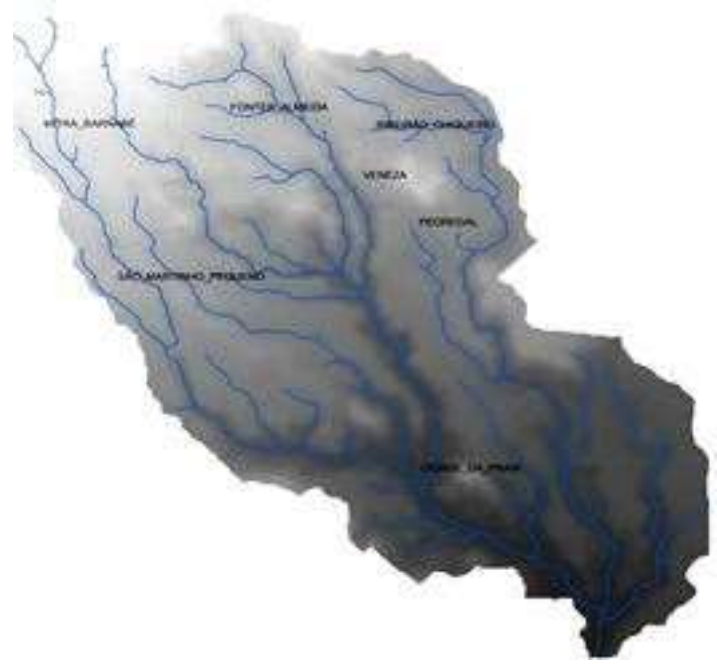

Fig.18: Basin flow at Praia county and the water volume drained in $\mathrm{m}^{3}$ during 450 minutes.

Figure 18 shows the discharge result from the precipitation data. This allows the water volume 
evaluation in cubic meters that crosses throughout the final section at intervals of 30 minutes for 8 hours. It is demonstrated that $76 \%$ of the precipitation volume stems from the flow coefficient that passed through the final part of the basin in 120 minutes and $99 \%$ crossed in 300 minutes.

Finally, Figure 19 shows the flow to the main basin, already reclassified at an equidistance of 30 minutes in terms of flow time. There is, however, some inconsistence of the results for the sectors with lower discharge that occurs further within the basin region, supposedly associated with areas of low permeability and rapid surface runoff.

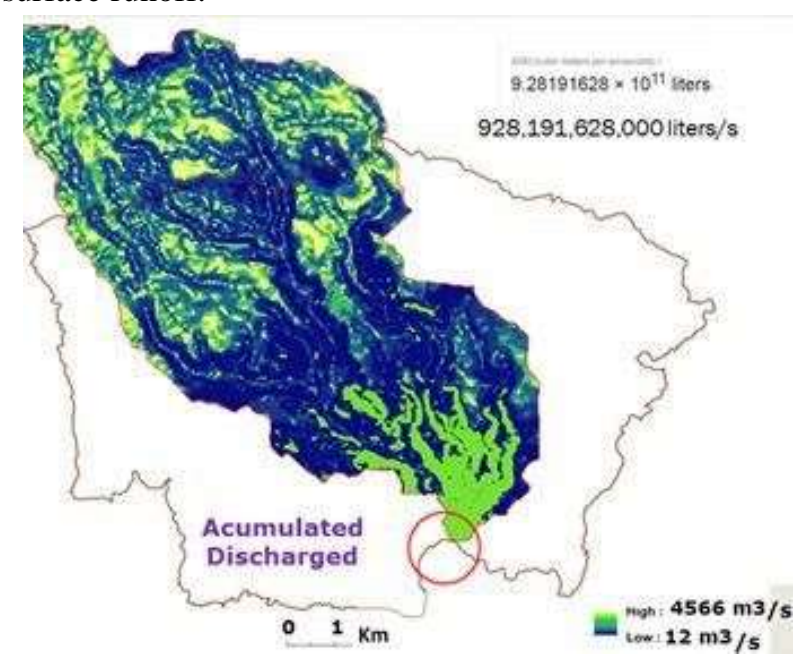

Fig. 19: Accumulated drain map where almost one trillion litters of water per second was the top accumulated discharged assessed by this study on the mouth of the Safende river.

\section{CONCLUSION}

In the county of Praia, there is a large population growth living under a hydrological risk area, especially along the water streams. The morphology and configuration of the surface runoff network in the surrounding areas of this county increase that risk mainly due to the confluence of several basins that flow into the urban area. Indeed, the areas of greatest hydrological risks in the county of Praia are in the lowland areas (along the flow streams). Despite the existence of lateral protection dikes in these streams, there is water overflow in some zones (particularly in Vila Nova creek) because of the large amount of material carried from the slopes and the highland areas of Fontes Almeida, St. Martinho and Mitra Barnabé. Moreover, there is a certain shortage of infrastructures for torrential correction in several ramps of the city and along the side protection dikes delimiting the rivers, where one can find a high density of soil occupation, especially in the settlements of San Pedro, Safende, Calabaceira, Vila Nova and Fazenda.
In this sense, it is recommended interventions in these risk areas in order to protect households that are at the edge of these flood lines, despite the financial costs. The intervention on these slopes becomes a priority in order to change the arrangement of the surface runoff lines. This involvementmay consist of afforestation and construction of grooves to prevent excessive transport of soil debris toward the low lying areas of the city during precipitation. Certainly, GIS solutions can play an essential tool for the surveillance and prevention of hydrological phenomena in this municipality. GIS adds a set of spatial information, facilitating the identification of existing vulnerabilities. For example, in this project we tried to define a model to characterize the hydrological risk flexible enough to operate at different scales or to be applied in other geographical areas with the necessary adjustments. Municipal authorities are, therefore, in a position to setup a warning and risk prevention system, as well.

\section{REFERENCES}

[1] Pedrosa\&Perreira (2005). Diagnóstico dos factores condicionantes das susceptibilidade face ao risco de inundação urbano no concelho de Matosinhos. Territorium.

[2] Nascimento, J. (2009). La croissance et le système de gestion et de planification de la ville de Praia. Universite de Rouen: Tese de Doutoramento.

[3] Amaral, I. (1964). Santiago de Cabo Verde.A Terra e os Homens. Lisboa: Memórias da Junta de Investigação do Ultramar.

[4] Silva, J., Monteiro, P., Negreiros, J.: Spatial Modulation of Rainfall in Santiago, Cabo Verde, with Geostatistical Analyst, International Association for the Scientific Knowledge InterTIC International Conference, Pedro Acosta \&Pedro Cravo (Eds), ISBN 978-989-06-04, pp. 272-276, Oviedo, Spain (Dec 10).

[5] Lelièvre, M. A. (2009). L'approche hydrogéomorphologique pour la cartographie des zones à risque d'inondation dans les vallées de petites et moyennes tailles: un exemple commenté pour la vallée de la rivière-au-renard. Géorisques IV Geohazardes. Georisques IV Geohazardes.

[6] Gesller, P. (1996). Modeling soil-landscape and ecosystem proprieties using terrain attributes. Australian National University.

[7] Ferraz, B. F., Milde, L. \& Mortatti, J. (1999). Hydrologic models attached to Geographic Information Systems: a case study. Revista de de Ciência \& Tecnologia. 
[8] Jones, R. (2002). Algorithms for using a DEM for mapping catchment areas of stream sediment samples. Computers \& Geosciences.

[9] Santana, I. D. (2010). Modelo hidrológico NGFLOW aplicado à bacia hidrográfica do Alto Aroguaia.

[10] Jain, K. \& Mishra, K. (2006). Evaluation of AMCdependent SCS-CN-based models using watershed characteristics.Water Resources Management.

[11] Natural Resources Conservation Service (2010). Hidrology National Engeenering Handbook. USA: Unite States Department of Agriculture.

[12] Tucci, C. (2002). Hidrologia: ciência e aplicação. Editora UFRGS/ABRH.

[13] Jong, S. M. (2006). Remote Sensing Image Analysis, Springer.

[14] Petty (1995). The Status of Satellite-Based Rainfall.Remote Sensing of Enviroment.

[15] Nobre, A. (2009). Sistema de informação geográfica de meteorologia e oceanografia para apoio operacional. Lisboa.

[16] Avila, A. (2006). Estimativa de precipitaçãoemregiõestropicaisutilizando imagens do satélite GOES 12. Campinas.

[17] Collischonn, J. (2007). Estimativas de precipitaçãoporsensoriamentoremotopassivo: desempenho do satélite TRMM naBacia do Alto ParaguaiatéDescalvados. Porto Alegre.

[18] Kuligowski, R. (2003). Status and Outlook of Operational Satellite Precipitation Algorithms for Extreme-Precipitation Events.American Meteorological Society.

[19] Cashiona, J. (2004). Microwave remote sensing of soil moisture: evaluation of the TRMM microwave imager (TMI) satellite for the Little River Watershed Tifton, Georgia. Journal of Hydrology, 243.

[20] Nobrega, R. (2008). Análise da estimativa de precipitação do trmmemuma sub-bacia da amazôniaocidental. Revista de Geografia. Recife.

[21] Behrangi, A. (2009). PERSIANN-MSA: A Precipitation Estimation Method from SatelliteBased Multispectral Analysis. Journal of hydrometeorology, 1414-1429.

[22] Arkin, P. \&Meisner, B. (1987). The relationship between large-scale convective rainfall and cold cloud over the Western Hemisphere during 198284. Mon. Wea. Rev, pp. 51-74.

[23] INMG (2003). Instituto Nacional de Meteorologia e Geofísica.Clima de Cabo Verde.
[24] UNESCO (1988). Soil map of the world: revised legend. World Soil Resources Report 60. Roma, Itália. 